\title{
Diet, Nutrition and Cardiovascular Disease: The Role of Social Determinants
}

\author{
ARUN PULIKKOTTIL JOSE ${ }^{1}$, KRITHIGA SHRIDHAR ${ }^{1}$ and DORAIRAJ PRABHAKARAN ${ }^{1,2, *}$ \\ ${ }^{1}$ Centre for Chronic Conditions and Injuries, Public Health Foundation of India, Gurgaon, Haryana, \\ India \\ ${ }^{2}$ London School of Hygiene and Tropical Medicine, London, UK
}

(Received on 19 June 2018; Accepted on 06 July 2018)

\begin{abstract}
Cardiovascular diseases (CVD) arethe leading cause of disability and mortality in India with ever increasing trends. The ubiquitous prevalence of CVD risk factors, despite some heterogeneity across different social strata, urban-rural locations and geographical regions, has been proven in several studies. Diet and nutrition have played a definitive role in this phenomenon. As India grapples with a dual burden of under- and over-nutrition, social factors at multiple levels such as individual's education and income, local food environment, migration and urbanization of populations, national agricultural produce and policies as well as global trade policies have complex relationships with diet as well as CVD. A deeper understanding of these factors is vital in designing public health interventions that are more targeted and relevant for the Indian population. Policy changes and community interventions based on societal needs may be necessary if we are to achieve the sustainable development goal targets by 2030 , benefitting the larger population.
\end{abstract}

Keywords: Diet; Nutrition; Cardiovascular Disease; Social Factors; India

\section{Introduction}

Cardiovascular diseases (CVD) are the leading cause of disability and mortality in the World. In 2016, 353.1 million disability adjusted life-years (DALYs) and 17.6 million deaths were estimated to be due to CVDwith over a third from low-middle income countries (LMICs) (Global Burden of Disease (GBD) Study, 2016). India, with 65.6 million DALYs and 2.74 million deaths due to CVD accounted for approximately half of LMICs' burden. Nearly a third of all deaths $(28.1 \%)$ in India were due to CVD, with over $50 \%$ dying prematurely between ages 30 and 69 years (GBD Study, 2016). Globally, over two decades (19902015), while CVD burden (disability and mortality) either increased modestly or notably declined in many geographical regions, Indian trends have shown steep increases $(53 \%$ in deaths and $41.5 \%$ in premature deaths between 2005 and 2016) (GBD Study, 2016; Prabhakaran et al., 2016; Roth et al., 2017). Despite some heterogeneity, CVD risk factors such as high blood pressure, overweight, obesity, abnormal blood lipid and glucose levels have become prevalent among men and women of all socioeconomic strata (SES) of urban and rural Indian populations (Prabhakaran et al., 2016; NFHS, 2015-16).

Diet, nutrition and physical activity are key modifiable determinants of CVD, potentially influencing risk of developing the disease by modulating blood pressure, blood levels of lipids, inflammation and fasting glucose as well as functions of the heart (Prabhakaran et al., 2016). As India grapples with a dual burden of under- and overnutrition (NFHS, 2015-16), over the last two decades, rapid changes in dietary habits and patterns have further complicated the scenario (Prabhakaran et al., 2016). In light of the need to achieve sustainable development goals by the year 2030 (e.g., one-third reduction in premature deaths), it is of utmost importance to understand the underlying factors influencing diet and nutrition in the Indian population. 


\section{Healthy Diet, Indian Dietary Patterns and Dietary Transition}

Based on extensive evidence, a healthy dietary pattern for individual and population cardiovascular health has been defined as one that is "high in vegetables, fruits, whole grains, sea food and fatty fish, legumes and nuts; moderate in low-fat and non-fat dietary products; lower in red and processed meat, refined grains and foods and beverages containing added sugars" (Pan et al., 2018). Further it is essential to consume low salt diet. Thus, World Health Organisation recommends 5 portions of fruits and vegetables a day, whole grains and nuts, $<10 \%$ of total energy intake from free sugars, $<30 \%$ of total energy intake from fats (less saturated and trans-fats) and $<5 \mathrm{~g}$ of iodized salt every day (WHO, 2018) for cardiovascular health along with physical activity of moderate intensity for at least 150 minutes in a week (WHO, 2018). Indians, conventionally an agrarian population largely consuming plant-based diet with less meat (e.g., the highest proportion of vegetarianism in the World is in India; about $10-60 \%$ across various regions of the country (NFHS, 2005-06, 2015-16; Fig. 1)), are presumed to experience less burden of CVD contrary to what is being observed today, but for two major reasons.
First, by and large, a typical Indian diet is rich in carbohydrates (largely refined cereals devoid of bran and germ and rich in starchy endosperm which enhance glycemic index), low quality proteins (largely from legumes inadequate for essential amino acid methionine), rich gravies (high in saturated fats and salt) and has low levels of fresh fruits, vegetables and pulses (Trichopoulou et al., 2014). In addition, the vegetables that are consumed are often overcooked in Indian meals, leading to vital loss of micronutrients (Trichopoulou et al., 2014). The indigenous dietary and cooking patterns in India are a blend of healthy and unhealthy components, for example, 'fruits-vegetables-sweets-snacks' pattern, 'whole grain-refined grain' pattern, energy-dense diets with fried snacks (deep fried with high salt and fat) (Green et al., 2016). According to National Family Health Survey (NFHS-4), a large nationally representative periodic cross-sectional survey covering 811808 individuals aged 15-49 years in India, the consumption of fruits and vegetables has been low with less than half of the population consuming vegetables, legumes or pulses everyday and less than $15 \%$ consuming fruits everyday in $2015-16$. This varied by urban-rural locations and social gradient, with individuals in urban and high SES consuming more than the rest. The trend has been consistent over the

\section{Prevalence of vegetarianism in India, National Family Health Survey (NFHS)}
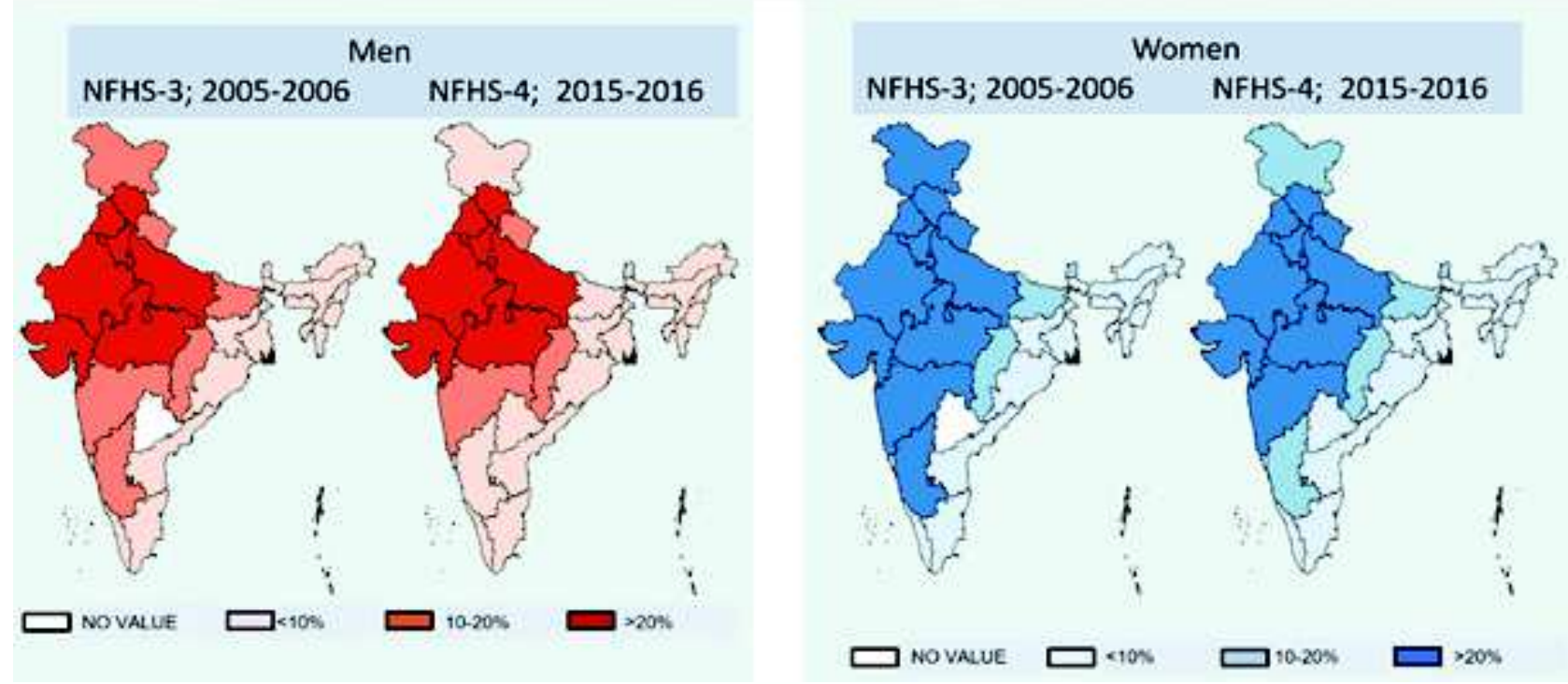

Fig. 1: Prevalence of vegetarianism in India National Family Health Survey (NFHS). Presented at $7^{\text {th }}$ International Congress on Vegetarian Nutrition, Feb, 2018 by Dr Preet K Dhillon, Public Health Foundation of India (reproduced with permission from Dr. Dhillon) 
last decade (2005-15), except for a further decline in the daily consumption of dark green, leafy vegetables among both women and men, with an increase in the daily consumption of milk or curd in 2015-16 (NFHS, 2015-16). Moreover, people living in low SES sustain themselves on an affordable diet, which contains little fat but is high on many refined carbohydrates such as white rice and refined wheat products, and salt (Pan et al., 2018, Prabhakaran et al., 2013). This assumes greater public health importance in the light of recent arguments on the quantitative beneficial influences of total fat and fat types (including saturated fat) on CVD risk among populations of low-middle income countries (Dehghan et al., 2017). The PURE study showed that consumption of saturated fats may even be protective in terms of mortality. The reasons for this inconsistency in the fats and cardio-metabolic relationship may be attributed to multiple reasons. All saturated fats are inherently different in their structure (long or medium chain, odd or even chain) and hence it becomes difficult to generalize results related to saturated fats. For example, saturated fats from dairy products that are usually odd chain maybe beneficial. Due to this complexity, saturated fats have shown differential effects on LDL cholesterol, HDL cholesterol, total cholesterol and triglycerides. Hence in the Indian context where food habits vary widely across states and refined grains contribute to almost $50 \%$ energy, it is essential to investigate the long-term effects of replacing refined grains with whole grains and good quality fat (e.g., dairy products in required portion size) for appropriate public health guidelines.

Second, dietary transition (Fig. 2), characterised by a decrease in intake of coarse cereals (e.g., millets), pulses, fruits and vegetables, an increasing intake of meat products, processed and ready-to-eat energy dense foods and salt, coupled with declining levels of physical activity (Misra et al., 2011), is a very important reason for rapidly increasing trends of CVD in Indian population. Dietary transition previously affecting urban, high SES populations has also penetratedinto the rural and low SES populations (Misra et al., 2011). Time-series data on nutrient intake captured from the National Sample Survey Organization surveys indicate that, despite little change in total calorie consumption from 1972 to 2000, Indians' fat intake increased in both rural and urban locations (Ramachandran, 2006). Partially hydrogenated vegetable oils with high trans-fat content contribute

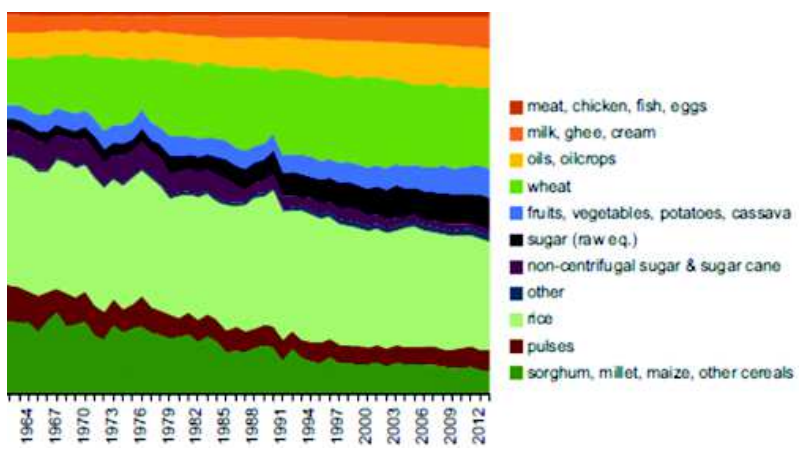

Fig. 2: Reproduced, with permission from Dr. Sutapa Agarwal, from herchapter "Geographic Aspects of Vegetarianism" (p. 100) in the book "Vegetarian and Plant-Based Diets in Health and Disease Prevention", I Edition, Publisher: Elsevier, Edited by: François Mariotti DOI: 10.1016/B978-0-12-803968-7.00006-X

to a significant proportion of total fat intake in Indians, particularly in urban adult slum dwellers (Mishra et al., 2001).

A simple explanation for these indigenous dietary habits and patterns as well as dietary transition can be awareness, availability, accessibility and affordability (4A's), governed by factors at multiple levels- individual level (education and income); community-level (local food environment, migration of population to regions and urbanization); national level (agricultural produce and policies) and at global level (globalization, trade policies, import-export and transnational food corporations).

\section{Individual and Community-level Factors}

Local food environment controls the decision to eat fruits-vegetables-pulses-fish vs. processed and readyto-eat food items vs. high intake of meat and is largely regulated by individual and community-level factors. While the availability and affordability of fruits and vegetables are limited in India, ready-to-eat food items are easily available at low cost. A household in a lowresource setting such as India on an average spends approximately $50 \%$ of its monthly income for 5 servings of fruits-vegetables/day/person (vs. $<2 \%$ in high income countries) (Miller et al., 2016). Although in urban locations, due to retail shops (street vendors and markets) and supermarkets with steady supply, the availability of fruits and vegetables is unrestricted compared to rural locations, consumption is low due to poor affordability. In rural areas the availability is 
limited to few varieties and despite local produce the affordability is limited by high costs at small local shops (Kanungsukkasem et al., 2009). Are cent household survey in South Urban Delhi reports that the availability and accessibility (accessible at short walk/ travel distance) are less of an issue compared to affordability of fruits and vegetables (Finzer et al., 2013). In rural locations while educated individuals tend to consume more fruits and vegetables affordability remains a major concern (Kanungsukkasem et al., 2009). Coupled to the problem is the lack of awareness across locations and socio-economic strata regarding adequate consumption of fruits and vegetables. In urban Delhi most households thought they ate enough fruits and vegetables while they actually consumed less (Finzer et al., 2013). In these households, only about $40 \%$ were aware of pesticide/chemical contamination in fruits and vegetables, and not all of them were able to afford higher prices for 'organic' alternatives (Finzer et al., 2013). Similarly, due to several factors at different levels, the availability and affordability of pulses, vegetables/fruits and fish are limited for the general Indian population.

Rapid urbanization, migration and mobilization of populations have made ready-to-eat food products easily available that are tasty, low cost alternatives, particularly targeting children. Although a qualitative study among 384 mothers in six Empowered Action Group (EAG) states observed that mothers perceived home-cooked food 'good', children demanded to have these purchased from the stores. These become convenient alternatives for home cooking for mothers due to severe time constraint and wide availability (Chaturvedi et al., 2016). Meat consumption, still largely influenced by culture, religion and tradition, has doubled from 2003-13. Religion and to some extent income, dominate the meat consumption pattern in India. While Hindus avoid beef, Muslims shun pork among the non-vegetarian populations in India. The rising trend of meat consumption can be explained by availability (India is the second largest exporter of red meat (beef, goat, sheep) in the World, affordability (low cost particularly some kind of poultry and due to economic growth of the population), urbanization and 'perceived' high status symbol. The increases for meat consumption are found to be greater than that of cerealsin India (Devi et al., 2014).
In the last decade when dietary transition was becoming evident, physical activity patterns were also changing in the Indian population across regions and locations. The prevalence of physical inactivity in India among adults aged $>20$ years which was low at $<15 \%$ in 2003-04, steeped to over 50\% in 2014 with $<10 \%$ engaging in physical activity at leisure times (any physical activity, if at all, was largely occupational) (Anjana et al., 2014). This was more apparent in urban areas (65\% vs. 50\% in rural areas), however the leisure activity was less in rural areas (Anjana et al., 2014). This could possibly be due to mechanized life-style, less physically demanding but timeconsuming occupations and increased income and availability of mechanized transport and household appliances. Certainly lack of awareness, despite education and income levels, and more importantly neighborhood factors such as lack of space due to rapid urbanization, inadequate foot path to walk or cycle, less leisure time due to long commutes and more demanding jobs, inadequate infrastructure for leisure time activities in the neighborhood are big concerns.

\section{Country-level Factors}

A larger perspective to these diet and nutrition issues stems from National level agricultural produce and policies. Green Revolution in India has ensured technology-based improvements in wheat and rice production and concomitant price reduction of cereals while increasing the relative prices of pulses and fish (Kadiyala et al., 2014). Pulses are mainly grown in marginal lands as intercrops with cereals and oilseeds. Only about $10-18 \%$ of farming land in India is devoted for pulses cultivation, with low yield rate of $<700 \mathrm{~kg} /$ ha (Joshi \& Rao, 2017). India is the largest consumer of pulses in the World, with pulses being imported from developed countries on a large-scale at high prices that have increased 1.5 fold over the last decade (Joshi \& Rao, 2017). So, affordable sources of energy (cereals) become the staple diet followed by relatively cheaper animal foods (poultry, red meat), dairy products, other (fish) animal sources of diet and last and least, fruit and vegetable or pulses (Kanungsukkasem et al., 2009). Per capita availability of legumes in India has decreased about $40 \%$ since 1990s (Gupta, 2012). On the other hand, the per capita availability of cereal and millets has increased. The cereal-to-pulse ratio has risen to $12: 1$ (ideal 8:1) 
(Ramachandran et al., 2007). Even though pulses production increased by $3 \%$ per year during the last decade, the cost of production and consequent prices have remained too high to be affordable for many people. Experts suggest that technological efforts need to be supported by the right policy environment to leverage research and development in agriculture (Gupta et al., 2009).

Agricultural produce is dependent on energy, water and land resource availability (Kadiyala et al., 2014) as well as other important aspects such as transport facilities (e.g., a cold-chain has to be maintained for transport of fruits and vegetables), crop price, yield (for example grains such as sorghum and millet give very low yield although need less water) and shelf-life (e.g., fruits and vegetables are biodegradable with less shelf-life compared to cereals) (Kadiyala et al, 2014). Water and land are increasingly transferred out of agriculture to provide for other demands of growing urban populations and crops needing large amounts of water may get affected. This along with National agricultural policies for resource allocation to farmers affect the nature of agricultural produce, not to mention the recent farmers' agitation where farmers demanded more support prices for fruits and vegetables' production and a co-operative market for sale. Inexpensive, culturally-acceptable and feasible interventions for boosting the fruit and vegetable consumption must be piloted and scaled up, if successful. Policy interventions, such as subsidies on growing and storing fruits and vegetables, can offer sustainable solutions for enhancing consumption among developing countries such as India (Prabhakaran et al., 2016).

\section{Global Factors}

Another key driver of the dietary transition in India has been the effect of globalization. The two plausible pathways that have been identified are the globalization driven changes in the food system and the social system (Hawkes et al., 2009). Globalization has an impact on all the components of the food system - its availability, pricing, production, processing, distribution and sale. It has played a role in influencing the supply as well as the demands of various foods in India. According to Hawkes et al. (2007), globalization exerts its influence on the food system mainly through three different ways - rise of transnational food corporations (TFCs), international food trade and the use of global food advertising and promotion.

In India, the effects of globalization were largely due to the liberalization of trade and Foreign Direct Investments (FDI). In the year 1991, India embarked on economic reforms that were characterized by liberalization of international trade and direct foreign investments. In 1994, India signed the Agreement on Agriculture of the General Agreement on Tariffs and Trade. Trade barriers were progressively brought down through 1990's right up until the year 2001 when all agricultural import barriers were lifted. Additionally several regional and bilateral agreements were also signed to facilitate free trade (Hawkes, 2007). It was thought that these measures would eventually improve domestic agriculture (Hawkes, 2007). However, an unexpected drop in international food prices in 1996/ 97 and changes in foreign exchange rates led to a decline in Indian agricultural exports and an increase in food-related imports especially vegetable oils, fruits, vegetables and pulses (Hawkes, 2007). In the year 2001, India was the world's largest importer of pulses (Price et al., 2003). More importantly, effects of the trade reforms started to reflect in food consumption patterns that showed a shift towards higher fat and lower carbohydrate (Hawkes, 2007). A rise in the consumption of vegetable oils corresponded with the increase in its import (e.g., palm oil consumption) (Hawkes, 2007).

The Industrial Policy of 1991 led to the liberalization of Foreign Direct Investments in India and the entry of Transnational Food Corporations (TFCs) into the Indian market space. TFC's have numerous influences on the food system in any country including food availability, pricing and preferences. Moreover, acquisition of domestic players by TFCs lead to the vertical integration and globalization of the food system (Hawkes et al., 2009). Further, globalization driven urbanization leads to the increase in demand of processed food especially in the time constrained urban middle income groups (Hawkes, 2007), which is now prevalent in economically weaker sections as well (Chaturvedi et al., 2016). Globalized food chains and TFC's usually invest in processed foods that are cheaper to produce, more profitable, easier to transport and have longer shelf lives as compared to raw unprocessed foods. With the emergence of supermarkets, the processed foods 
have become easily available at cheaper prices and are even promoted over primary unprocessed food (Hawkes et al., 2009). Consumers that usually purchase food from open markets that sold mostly home grown or locally produced food, find supermarkets more convenient and accessible (Chopra, 2002). Moreover, TFCs utilize media much more effectively to promote and target their products. It is often observed that most fast-food chains and sugar-sweetened beverage companies intentionally target children and youth in their marketing strategies (Hawkes et al., 2009).

The food system changes have been further enhanced by the globalization driven changes in the social system that includes urbanization, income growth and employment (Hawkes et al., 2009). Although globalization and free trade has allowed India's economy to grow rapidly in the post-liberalization era, changes are mostly unequally distributed and have affected various sections of the society differently. The urban middle-income group and skilled individuals have benefitted most from economic growth and rise in employment opportunities (Hawkes et al., 2009). Over time, the diet of the urban middle class is seen to converge increasingly with that of the Western world (Hawkes et al., 2009). On the other hand, the economic and employment gains of globalization have been minimal in the lower income and unskilled groups. Dependent on wages that are not indexed for inflation or the rise in food prices, this group remains unable to afford and avail of healthy food choices (Ghosh, 2002). Thus globalization has made energy dense poor quality diet accessible, affordable and preferable to the time strapped, rapidly urbanizing Indian population across all strata of living.

\section{Recommendations}

With multi-level issues affecting diet and nutrition of the Indian population, we may reach a stage that is not so desirable for the general population, i.e., "stage 3 of nutrition transition", where only some people (especially those belonging to the high socioeconomic strata with a capacity to buy expensive healthy food items and afford facilities for physical activity) are aware and try to adapt a healthy lifestyle (Misra A et $a l$.). For larger benefits at the population level, we need stronger recommendations today.

1. The first and foremost intervention would be to increase the awareness of healthy diet and physical activity among the population through a targeted and focused approach. Targeting children and adolescents through health promotion activities at schools could be an effective way to ingrain healthy behaviours in the early phase of life. As an example, awareness should be created regarding the utility of local and seasonal fruits and vegetables as part of a healthy diet. Further some good cultural practices such as using millets, use of different oils based on what is being cooked, an Indian practice should be preserved and promoted. The importance of harm caused by trans-fats, particularly deep fried foods, should be emphasized. Further, given the burgeoning obesity among the lower middle and higher classes, simple messages such as importance to portion sizes would need emphasis.

2. A second approach would be to target young adults through worksite intervention programs, especially in the urbanized populations. Considering the large portion of the day spent at the work place, implementing lifestyle change education and support at the worksite may be an effective and cost-effective method to deliver prevention in a way that is acceptable, accessible, and sustainable and overcomes barriers to lifestyle change (e.g., lack of time or resources). In a recent industrial worksite-based intervention program implemented in India (Prabhakaran et al., 2009; Jeemon et al., 2012), several cardiovascular risk factors were brought down using a combination of both populationwide as well as high-risk approaches. In this study, diastolic blood pressure, fasting plasma glucose, and total cholesterol each decreased by $>5 \%$ in the intervention sites, whereas they increased by $5 \%, 13 \%$, and $4 \%$, respectively, at the control site (Prabhakaran et al., 2009; Jeemon et al., 2012).

Yet another fine example of a nationwide health promotion campaign is the Mauritian Programme of "Inter-health initiative" launched in the year 1987 in response to rising trends of CVD burden in the country. The program included extensive use of the mass media and widespread community, school, and workplace health 
education activities in addition to fiscal and legislative measures. After five years, reductions in population blood pressure and serum lipid concentrations and increased leisure exercise, with decreased smoking and alcohol use were observed (Dowse et al., 1995). Further, a national level policy changing palm oil consumption to $100 \%$ soybean oil brought a pronounced improvement in population lipid profile.

3. Increased awareness has to be coupled with better availability and affordability. For example, promotion of physical activity should go handin-hand with provision of adequate infrastructure and friendly neighborhoods to increase the physical activity levels of the population. Better planning of urban areas with inclusion of green spaces, and better sidewalks would help in improving physical activity levels among the urban communities.

4. Policies to increase the availability and affordability of healthy food items should be recommended. For example,prevention of transport related losses of fruits and vegetables which can be as high as $50 \%$ and increasing their support prices to compensate for high biodegradability would help reduce costs as well as encourage farmers to invest time and resources on fruits-vegetables farming. Increasing land availability (from marginal lands to fertile lands) for pulses cultivation with improvements in yield and crop rotation strategies could result in higher production and consumption of legumes. The decline in deaths due to CVD in Poland since 1991, attributed to increased import of fruits and vegetables with decreased cost price at a population level, is a promising example of how better affordability and availability of healthier food options can have a direct influence on CVD burden (Zatonski et al., 1991).

5. Strong policy to limit the harmful effects of globalization should be put in place. While globalization is important for economic growth of the country, it is pertinent to limit the influences of global entities on the local food systems. Left unchecked, globalization and liberal trade policies have the potential to dictate food availability, affordability and preferences. As a first step, a ban on food advertisements targeting children and young adults should be implemented. Bold policies and restrictions must be imposed on media promoting unhealthy diets such as the ones placed on alcohol and tobacco in India. In France, over three-fourths of parents of children aged between 3 and 17 years supported a statutory regulation banning advertisements for excessively fatty, salty and sugary beverages and foods during television programmes targeting children and teenagers (Escalon et al., 2016).

6. High taxes or ban on unhealthy food items such as processed, ready-to eat food items, sugar sweetened beverages, trans-fat content should be implemented. In 2014, Mexico implemented at axonsugar-sweetened beverage (SSB) purchases of 1 peso/L. Subsequently, the purchases of SSB decreased $(6.3 \%)$ and water purchases $(16.2 \%)$ increased and the magnitude of change was higher among lower-income and urban households (Colchero et al., 2017). The Danish Nutrition Council's campaign convinced Danish policy makers that industrially produced trans-fat could be removed from foods without affecting taste, price or availability of foods which led to the total ban of trans-fat in packed food items in 2003(Astrup, 2006). Modeling studies have shown considerable benefits by imposition of taxes on tobacco, palm oil, and sugar-sweetened beverages in India. A 20\% tax on sugar-sweetened beverages is estimated to reduce overweight and obesity prevalence by $3 \%$ and the incidence of type 2 diabetes mellitus by $2 \%$ (Basu et al., 2014). It is also estimated that a $20 \%$ tax on palm oil purchases could potentially avert approximately 363,000 deaths from myocardial infarctions and strokes over a period of 10 years (Basu et al., 2013).

Lastly research in agriculture to produce abundant healthy foods needs emphasis. For example, developing low glycemic index and high fibre rice would be very useful.

\section{Conclusion}

Diet and nutrition have a significant influence on CVD burden in India. Several social factors at multiple 
levels(individual, community, National and Global) have complex relationships with diet as well as CVD. It is vital that we recognize and consider these factors while designing interventions. Public health measures, policy changes and community interventions that are

\section{References}

Anjana R M, Pradeepa R, Das A K, Deepa M, Bhansali A, Joshi S R, Joshi PP, Dhandhania V K, Rao PV, Sudha V, Subashini R, Unnikrishnan R, Madhu S V, Kaur T, Mohan V and Shukla D K (2014) ICMR-INDIAB Collaborative Study Group. Physical activity and inactivity patterns in India results from the ICMR-INDIAB study (Phase-1) [ICMRINDIAB-5] Int J Behav Nutr Phys Act 1126

Astrup A (2006) The trans fatty acid story in Denmark Atheroscler Suppl 7 43-6

Basu S, Babiarz K S, Ebrahim S, Vellakkal S, Stuckler D and Goldhaber- Fiebert J D (2013) Palm oil taxes and cardiovascular disease mortality in India: economicepidemiologic model $B M J 347 \mathrm{f} 6048$

Basu S, Vellakkal S, Agrawal S, Stuckler D, Popkin B and Ebrahim S (2014) Averting obesity and type 2 diabetes in India through sugar-sweetened beverage taxation: an economicepidemiologic modeling study PLoS Med 11 e1001582 doi: 10.1371/journal.pmed.1001582

Chaturvedi S, Ramji S, Arora N K, Rewal S, Dasgupta R, Deshmukh V; for INCLEN Study Group (2016) Timeconstrained mother and expanding market: emerging model of under-nutrition in India BMC Public Health 16632

Chopra M (2002) Globalization and food: Implications for the promotion of "healthy" diets. Geneva: World Health Organization

Colchero M A, Molina M and Guerrero-López C M (2017) After Mexico Implemented a Tax, Purchases of SugarSweetened Beverages Decreased and Water Increased: Difference by Place of Residence, Household Composition, and Income Level J Nutr 147 1552-1557

Danaraj T J, Acker M S, Danaraj W, Wong H O and Tan B Y (1959) Ethnic group differences in coronary heart disease in Singapore: an analysis of necropsy records Am Heart J $58516-526$

Devi S M, Balachandar V, Lee SI and Kim I H (2014) An Outline of Meat Consumption in the Indian Population - A Pilot Review Korean J Food Sci Anim Resour 34 507-15

Dehghan M, Mente A, Zhang X, Swaminathan S, Li W, Mohan V, Iqbal R, Kumar R, Wentzel-Viljoen E, Rosengren A, Amma more targeted and based on societal needs are necessary if we are to achieve the Sustainable Development Goal target of reducing the premature mortality due to cardio-vascular disease in Indians

LI, Avezum A, Chifamba J, Diaz R, Khatib R, Lear S, Lopez-Jaramillo P, Liu X, Gupta R, Mohammadifard N, Gao N, Oguz A, Ramli AS, Seron P, Sun Y, Szuba A, Tsolekile L, Wielgosz A, Yusuf R, Hussein Yusufali A, Teo K K, Rangarajan S, Dagenais G, Bangdiwala S I, Islam S, Anand S S, Yusuf S; Prospective Urban Rural Epidemiology (PURE) study investigators. Associations of fats and carbohydrate intake with cardiovascular disease and mortality in 18 countries from five continents (PURE): a prospective cohort study Lancet 2017; 390 2050-2062

Dowse G K, Gareeboo H, Alberti K G, Zimmet P, Tuomilehto J, Purran A, Fareed D, Chitson P and Collins V R (1995) Changes in population cholesterol concentrations and other cardiovascular risk factor levels after five years of the noncommunicable disease intervention programme in Mauritius. Mauritius Non-communicable Disease Study Group BMJ 311 1255-9

Escalon H, Cogordan C and Arwidson P (2016) Parents support for the ban on television food advertising to children is particularly high in France, especially compared to the USA. This result should influence political decisionmaking to restrict food marketing targeting young people Sante Publique 28 7-17

Finzer L E, Ajay V S, Ali M K, Shivashankar R, Goenka S, Sharma P, Pillai D S, Khandelwal S, Tandon N, Reddy K S, Narayan K M and Prabhakaran D (2013) Fruit and vegetable purchasing patterns and preferences in South Delhi Ecol Food Nutr 52 1-20

Ghosh J (2002) Social policy in Indian development. Geneva: United Nations Research Institute for Social Development (UNRISD). Retrieved from: http:// unrisd.org/unrisd/ website/document.nsf/ab82a6805797760f80256b4f $005 \mathrm{da} 1 \mathrm{ab} / 7 \mathrm{ee} 221555523155 \mathrm{dc} 1256 \mathrm{c} 77003 \mathrm{cfaed} /$ SFILE/ ghoslong.pdf

Global Burden of Disease Collaborative Network. Global Burden of Disease Study 2016 (GBD 2016) Results. Seattle, United States: Institute for Health Metrics and Evaluation (IHME), 2017. Available from http://ghdx.healthdata.org/ gbd-results-tool

Green R, Milner J, Joy E J, Agrawal and Dangour A D (2016) Dietary patterns in India: A systematic review Br J Nutr 
$116142-8$

Gupta S (2012) Food expenditure and intake in the NSS 66th round - Economic and Political Weekly. Available at: http:/ /www.epw.in/commentary/foodexpenditure-and-intakenss-66th-round.html

Gupta R, Misra A, Vikram N K, Kondal D, Gupta S S, Agrawal A and Pandey R M (2009) Younger age of escalation of cardiovascular risk factors in Asian Indian subjects $B M C$ Cardiovasc Disord 928

Hawkes C (2007) WHO Commission on Social Determinants of Health. Globalization, Food and Nutrition Transitions. Globalization and Health Knowledge Network, Research Papers. Ottawa: Institute of Population Health

Hawkes C, Chopra M and Friel S (2009) Globalization, Trade, and the Nutrition Transition. Globalization and Health: Pathways, Evidence and Policy 2009. 10.4324/ 9780203881026

Jeemon P, Prabhakaran D, Goenka S, Ramakrishnan L, Padmanabhan S, Huffman M, Joshi P, Sivasankaran S, Mohan B V, Ahmed F, Ramanathan M, Ahuja R, Sinha N, Thankappan K R and Reddy K S (2012) Sentinel Surveillance in Industrial Populations Study Group. Impact of comprehensive cardiovascular risk reduction programme on risk factor clustering associated with elevated blood pressure in an Indian industrial population Indian J Med Res 135 485-493

Joshi P K and Rao P P (2017) Global pulses scenario: Status and outlook Ann N Y Acad Sci 1392 6-17

Kadiyala S, Harris J, Headey D, Yosef S and Gillespie S (2014) Agriculture and nutrition in India: Mapping evidence to pathways Ann N Y Acad Sci 1331 43-56

Kanungsukkasem U, Ng N, Van Minh H, Razzaque A, Ashraf A, Juvekar S, Masud Ahmed S and Huu Bich (2009) Fruit and vegetable consumption in rural adults population in I DEPTH HDSS sites in Asia Glob Health Action 282

Miller V, Yusuf S and Chow C K (2016) Availability, affordability, and consumption of fruits and vegetables in 18 countries across income levels: findings from the Prospective Urban Rural Epidemiology (PURE) study Lancet Glob Health 4 e695-703

Misra A, Singhal N, Sivakumar B, Bhagat N, Jaiswal A and Khurana L (2011) Nutrition transition in India: secular trends in dietary intake and their relationship to diet-related non-communicable diseases J Diabetes 3 278-92

Misra A, Sharma R, Pandey R M and Khanna N (2001) Adverse profile of dietary nutrients, anthropometry and lipids in urban slum dwellers of northern India Eur J Clin Nutr $\mathbf{5 5}$ $727-734$
National Family Health Surveys 2005-06 and 2015-16. Available at http://rchiips.org/nfhs/; accessed on $14^{\text {th }}$ June 2018

Pan A, Lin X, Hemler E and Hu F B (2018) Diet and Cardiovascular Disease: Advances and Challenges in Population-Based Studies Cell Metab 27 489-496

Prabhakaran D, Jeemon P, Goenka S, Lakshmy R, Thankappan K R, Ahmed F, Joshi P P, Mohan B V, Meera R, Das M S, Ahuja R C, Saran R K, Chaturvedi V and Reddy K S (2009) Impact of a worksite intervention program on cardiovascular risk factors: A demonstration project in an Indian industrial population $\mathrm{J}$ Am Coll Cardiol 53 17181728 doi: 10.1016/j.jacc.2008.12.062

Prabhakaran D, Jeemon P and Reddy K S (2013) Commentary: Poverty and cardiovascular disease in India: do we need more evidence for action? Int J Epidemiol 42 1431-5

Prabhakaran D, Jeemon P and Roy A (2016) Cardiovascular Diseases in India. Current Epidemiology and Future Directions Circulation 133 1605-1620

Price G K, Landes R and Govidan A (2003) India's Pulse Sector: Results of Field Research. Washington DC: United States Department of Agriculture

Ramachandran P (2006) The Double Burden of Malnutrition in India. ftp://ftp fao.org/docrep/fao/009/a0442e/a0442e01. pdf. Rome, Italy; Food and Agriculture Organization

Ramachandran A, Ramachandran S, Snehalatha C, Augustine C, Murugesan N, Viswanathan V, Kapur A and Williams R (2007) Increasing expenditure on health care incurred by diabetic subjects in a developing country: a study from India Diabetes Care 30 252-256

Roth G A, Johnson C, Abajobir A et al. (2017) Global, Regional, and National Burden of Cardiovascular Diseases for 10 Causes, 1990 to $2015 \mathrm{~J} \mathrm{Am} \mathrm{Coll} \mathrm{Cardiol} 70$ 1-25

Trichopoulou A, Martínez-González M A, Tong T Y, Forouhi N G, Khandelwal S, Prabhakaran D, Mozaffarian D, de Lorgeril M Definitions and potential health benefits of the Mediterranean diet: views from experts around the world. BMC Med. 2014 Jul 24; 12112

WHO Healthy diet. Available at http:/www.who.int/news-room/ fact-sheets/detail/healthy-diet. Accessed on $14^{\text {th }}$ June 2018

WHO physical activity recommendations. Available at http:// www.who.int/dietphysicalactivity/factsheet_ recommendations/en/ Accessed on $14^{\text {th }}$ June 2018

Zatonski W A, McMichael A J and Powles J W (1998) Ecological study of reasons for sharp decline in mortality from ischaemic heart disease in Poland since 1991 BMJ 316 1047-51. 